\title{
Effects of mixed liquor suspended solid concentrations on membrane bioreactor efficiency for treatment of food industry wastewater
}

\begin{abstract}
This study investigated the impact of mixed liquor suspended solid (MLSS) concentrations on the performance of a membrane bioreactor for treating food industry wastewater. The membrane bioreactor was mainly made up of an activated sludge reactor and microfiltration hollow-fibre membrane. Two experimental procedures consisting of low and high MLSS concentrations were set up. The process at low MLSS concentrations provided a higher degree of treatment in terms of suspended solids (99.2\%) and turbidity (99.73\%) removals. The mean flux value of process at low MLSS concentrations $(5.03 \mathrm{~L} / \mathrm{m} 2 . \mathrm{h})$ was found higher than those at high MLSS concentrations $(2.27 \mathrm{~L} / \mathrm{m} 2 . \mathrm{h})$. Furthermore, the effectiveness of MLSS concentrations was greatly influenced by the position of the membrane modules. Higher turbidity and suspended solids removals and higher flux values were obtained with a horizontally positioned membrane module compared to a vertically placed membrane module.
\end{abstract}

Keyword: Membrane bioreactor; Activated sludge; Wastewater treatment; MLSS; Mixed liquor suspended solids; Microfiltration 